\title{
Verificação da Aplicação de Boas Práticas de Fabricação e Avaliação da Qualidade Microbiológica de Alimentos Produzidos em Restaurantes Japoneses em Divinópolis/MG
}

\author{
Anna Paula Rodrigues Lopes (I), Juliana Magalhães (I) \\ (I) UFSJ - Universidade Federal de São João del Rei (Rua Sebastião Gonçalves Coelho, 400 \\ Bairro Chanadour, Divinópolis/MG)
}

\section{Resumo}

Os aspectos higiênico-sanitários da produção da comida japonesa são fatores preocupantes por ser um produto altamente perecível. Sabe-se que dentre as principais causas de DTAs de origem microbiana está a manipulação inadequada dos alimentos. Sendo assim, pela forma de preparo e consumo desses alimentos, estes ficam expostos a diversos contaminantes associados a práticas incorretas de manipulação. Este trabalho visou avaliar as condições de higiene de dois restaurantes japoneses da cidade de Divinópolis-MG, através da aplicação de checklist e da qualidade microbiológica de alguns alimentos produzidos, bem como conscientizar e orientar os manipuladores de alimentos quanto à aplicação das BPFs neste setor. O checklist foi elaborado segundo a Resolução RDC 216/2004 e o Anexo II da Resolução RDC 275/2002, ambos provenientes da ANVISA, que dispõem sobre a Lista de Verificação das BPFs em Estabelecimentos Produtores/Industrializadores de Alimentos. Os itens avaliados foram: (1) "Edificação e instalações"; (2) "Equipamentos e utensílios"; (3) "Manipuladores" e (4) "Produção e transporte do alimento". Para avaliar a qualidade microbiológica dos alimentos foram coletadas amostras de seis tipos de sushi, além de molho shoyo, gengibre, pepino e erva forte. Os microrganismos analisados foram coliformes fecais, S.aureus e Salmonella, segundo Silva et al (2010). Os resultados do checklist mostraram que ambos os restaurantes apresentaram a maioria dos itens em

\footnotetext{
Referência:

Anna Paula Rodrigues Lopes, Juliana Magalhães. Verificação da Aplicação de Boas Práticas de Fabricação e Avaliação da Qualidade Microbiológica de Alimentos Produzidos em Restaurantes Japoneses em Divinópolis/Mg. In: Anais do $12^{\circ}$ Congresso Latinoamericano de Microbiologia e Higiene de Alimentos - MICROAL 2014 [= Blucher Food Science Proceedings, num.1, vol.1]. São Paulo: Editora Blucher, 2014. 
conformidade com o exigido, com destaque ao item 1. Os demais itens apresentaram mais de $65 \%$ de adequação. $O$ restaurante 1 apresentou Salmonella e S.aureus fora dos padrões nos sushis com cream cheese e frito. No outro restaurante, este microrganismo foi encontrado apenas no sushi com cream cheese. Já no restaurante 2, além dos sushis frito e com cream cheese, sua presença foi detectada no sushi com kani. Coliformes fecais foram encontrados no sushi frito no restaurante 1. As amostras de molho shoyo, gengibre, pepino e erva forte não apresentaram crescimento microbiano fora dos padrões. Observou-se, portanto, que, apesar do emprego das BPFs pelos estabelecimentos, alguns alimentos se encontravam inadequados ao consumo. Além disso, a presença de microrganismos no sushi frito indica contaminação após a fritura, uma vez que eles são sensíveis a temperatura, indicando assim, falhas nas BPF.

Palavras-Chave: comida japonesa, condições higiênicas, checklist Agência de Fomento: CNPq, Fapemig, UFSJ 